\title{
Hydraulic resistance of the packing for biofilters in the viscous flow regime of the gas stream
}

\author{
Aleksandr Mitin, Natalia Nikolaikina, Aleksandr Pushnov \\ Moscow state university of mechanical engineering, Bolshaya Semenovskaya str., 38, Moscow, 107023, Russia
}

\begin{abstract}
In the paper, the hydrodynamics of existing packings for biofilters is considered. The paper discusses the features of the flow regime of the gas stream in the random packings and regular packings at Reynolds numbers (from 15 till 200) that correspond to the viscous flow regime in the processes of biological purification of the gas. Results of research of hydraulic resistance of packings from artificial materials (combinated packing, highly porous packing, polyurethane foam, ceramic raschig rings, recovered carbon, silicagel) and natural materials (lump wood, cone, bark) are given. These packings are widely used in the heat-mass transfer devices. The experiments were carried out on the experimental columns. Diameters of the columns are 100 and $200 \mathrm{~mm}$. Height of the columns is $1000 \mathrm{~mm}$. The results of experiments are generalized using similarity criteria - Reynolds. Obtained regularities enable one to select the most efficient and less energy-consuming modes of operation of the biofilter. The packings of a various geometrical form are compared. In addition, classification the packings for biofilters is given. The most perspective packings for implementation of biological gas purification are offered.
\end{abstract}

Keywords: biofilter; packing; purification of gas; viscous; inertial flow regime.

\section{Introduction}

Biological purification of air - the most eco-friendly technology, currently in use to remove as various organic pollutants and odors [1, 2, 3]. Biofiltration process is mass-transfer. In the biofilter active agent are microorganisms which are supported on an inert carrier-packing. Hydrodynamic process conditions and the design of packing element largely influence the intensity and energy of the biological purification of gas. The hydrodynamic characteristics of the process of biofiltration are small gas flow rates (up to $1 \mathrm{~m} / \mathrm{s}$ ), small Reynolds number (15-200), the frequency of irrigation. In this connection, it was assumed viscous flow regime of the gas stream in the biofilter, in which the influence of inertial forces becomes negligibly low compared to the forces of viscosity. Therefore, mode process enables construction of the packing with a high specific surface area, which is a necessary condition for the possibility of a highly efficient process. Determination of hydrodynamic regime allows to determine the pressure loss on the packing. This is very important because the process must be used biofiltration packing with high specific surface, which can potentially have a large hydraulic resistance.

\section{Methodology}

\subsection{Theoretical part}

In the process of biofiltration as mass transfer processes interacting with gas and liquid phases have been various hydrodynamic regimes outlined precise boundaries. At values of the Reynolds number, related to the diameter of the channel $-R e_{d}<2300$ viscous forces dominate and the pressure drop is determined entirely by friction against the walls of the flow channels [4]. In determining the precise boundaries of the hydrodynamic regime of the process is possible to optimize the process of biofiltration. Consider the theoretical side of the question.

Corresponding author: Aleksandr Pushnov. E-mail address: mitin.rus@gmail.com

http://dx.doi.org/10.3846/enviro.2014.037

(C) 2014 The Authors. Published by VGTU Press. This is an open-access article distributed under the terms of the Creative Commons Attribution License, which permits unrestricted use, distribution, and reproduction in any medium, provided the original author and source are credited. 
To calculate the hydraulic resistance of the layer random packing used different equations. The most common form is [5, $6,7]$ :

$$
\Delta P=\zeta \frac{H}{d_{e}} \cdot \frac{\rho}{2} \cdot\left(\frac{W_{0}}{\varepsilon}\right)^{2}
$$

since:

$$
d_{e}=4 \varepsilon / a
$$

where:

$\varepsilon$ - the void fraction of the bed (bed porosity at any time), $\mathrm{m}^{3} / \mathrm{m}^{3}$;

$\rho$ - the gas density, $\mathrm{kg} / \mathrm{m}^{3}$;

$W_{0}$ - the gas velocity, $\mathrm{m} / \mathrm{s}$;

$a$ - the specific surface, $\mathrm{m}^{2} / \mathrm{m}^{3}$;

$H$ - the packed bed height, $\mathrm{m}$;

$\zeta$ - flow friction characteristic.

After substitution of the expression (2) in equation (1) and simplest transformations, we obtain:

$$
\frac{\Delta P}{H}=\zeta \cdot \frac{a \cdot \rho \cdot W_{0}^{2}}{8 \varepsilon^{3}}
$$

For further analysis on the effect of flow of the gas stream in the layer dry packing on the magnitude of the hydraulic resistance is useful Ergun equation, which has the form [8]:

$$
\frac{\Delta P}{H}=A \cdot \frac{(1-\varepsilon)^{2}}{\varepsilon^{3}} \cdot \frac{\mu \cdot W_{0}^{2}}{d^{2}}+B \cdot \frac{(1-\varepsilon)}{\varepsilon^{3}} \cdot \frac{\rho \cdot g \cdot W_{0}^{2}}{d},
$$

where:

$\mu$ - the dynamic viscosity of the fluid, $\mathrm{m}^{2} / \mathrm{s}$;

$g$ - gravity acceleration, $\mathrm{m} / \mathrm{s}^{2}$;

$d$ - the equivalent spherical diameter of the packing, $\mathrm{m}$;

$A, B$ - coefficients.

The equation (4) has a definite physical meaning. The coefficients $(A$ and $B)$ in this equation describe, respectively, viscous and inertial flow regimes of gas stream in the packing layer. According to the paper [8] viscous flow regime of gas stream in the packed bed correspond to the Reynolds number $-R e<40$, and the field dominance of inertial forces $-R e>40$.

Here:

$$
\operatorname{Re}=\frac{4 \cdot W_{0} \cdot \rho}{a \cdot \mu}
$$

After replacing $a$ in the formula (5) in equation (2) we obtain:

$$
\operatorname{Re}_{d_{e}}=\frac{W_{0} \cdot d_{e} \cdot \rho}{\varepsilon \cdot \mu}
$$

On the basis of experimental data, that the upper boundary of the viscous flow regime of the gas stream in the apparatus, the completed by packing, a following range of values: $\operatorname{Re}_{d e}=40-60$ [4].

Under the conditions of the flow regime of gas stream, where viscous forces dominate, the magnitude of loss of pressure in the packing layer is determined by the flow of the friction surface geometric curvilinear channels formed by a set of a plurality of packing elements. Along with a specific surface area important hydrodynamic feature packed bed is a "living" section of the channels packing is numerically equal to the value of porosity (percentage of free volume) packed bed. Indeed, in expanded form, the following chain of transformations can represent equation (2). First of all, the characteristic linear size of the packing layer - equivalent diameter $d e$ equal to four times the channel hydraulic radius:

$$
d_{e}=4 R=4 F / P \text {, }
$$

where,

$R$ - the hydraulic radius, $\mathrm{m}$;

$F$ - the total cross sectional area of the channel in the packed bed, $\mathrm{m}^{2}$;

$P$ - the perimeter of the packing channel cross-section, $\mathrm{m}$;

$H$ - the height running meter of packed bed, $\mathrm{m}$.

$$
\begin{aligned}
& F \cdot H=\varepsilon ; \\
& P \cdot H=a .
\end{aligned}
$$


Thus, the expression (7) has the form:

$$
d_{e}=4 F / P=4 F \cdot H /(P \cdot H)=4 \varepsilon / a .
$$

Appeal to impact analysis the magnitude of bed void fraction $\varepsilon$ on the head loss $-\Delta P$. With reference to the case in the viscous flow regime equate the coefficient $B$ in equation (4) to zero. Let us also for purely qualitative evaluation $A=1,=1$, $d=1, H=1, W_{0}=1$.

Then:

$$
\Delta P \approx \frac{(1-\varepsilon)^{2}}{\varepsilon^{3}} .
$$

For the inertial flow regime, respectively, in equation (4), the coefficient $A$ equate to zero and $B=1, \mu=1, d=1, H=1$, $W_{0}=1$.

Then:

$$
\Delta P \approx \frac{1-\varepsilon}{\varepsilon^{3}}
$$

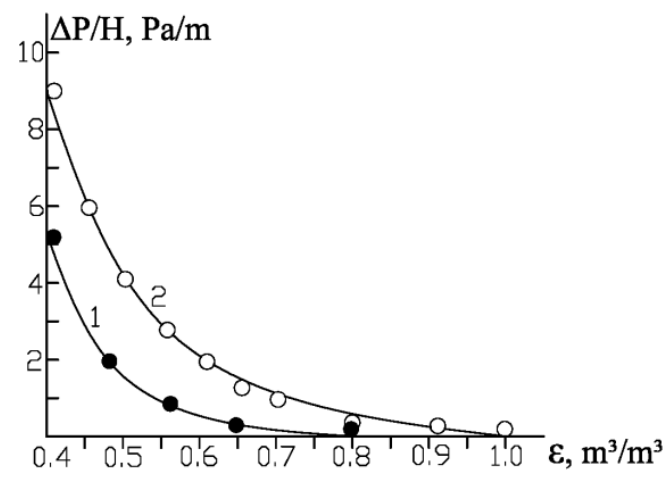

Fig. 1. The qualitative dependences of the form $\Delta P / H=f(\varepsilon)$ to appropriate flow regimes in the layer of packing:

1 - viscous flow regime, the calculation according to the equation (11);

2 - inertial flow regime, the calculation according to the equation (12)

Thus obtained purely qualitative dependence $(\Delta P / H)=f(\varepsilon)$ for these two flow regimes of gas flow in the packing layer - viscous and inertial shown on figure 1. From the graphs on figure 1 shows that with increasing the void fraction of the bed value (living section packed bed) and thus decrease the velocity of the gaseous fluid being filtered, the pressure loss, respectively, decreased.

\subsection{Experimental setup and materials}

For the experiment to determine the hydrodynamic regime biofiltration process were selected the most appropriate packing. Also participated in the experiments design packing of his own invention. Images of these packings are presented on figure $2 a$ and $2 b$. After hydraulic testing our patented packings were tested for the degree of efficiency. The effectiveness of our packings for deodorization ventilation emissions of tobacco on a formed by the packing (Figure 2a) biocatalyst approaching $99 \%$ under laboratory conditions at clearing air from dichloromethane to $90 \%$ [9].

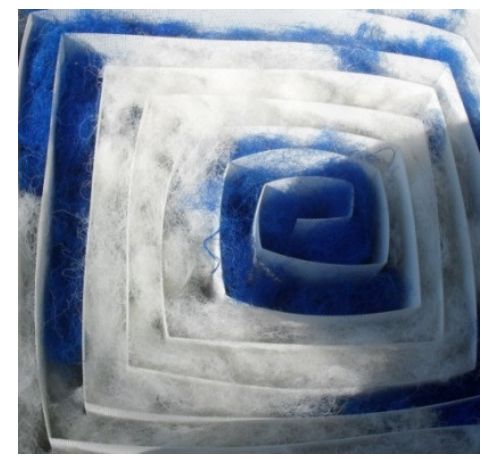

(a)

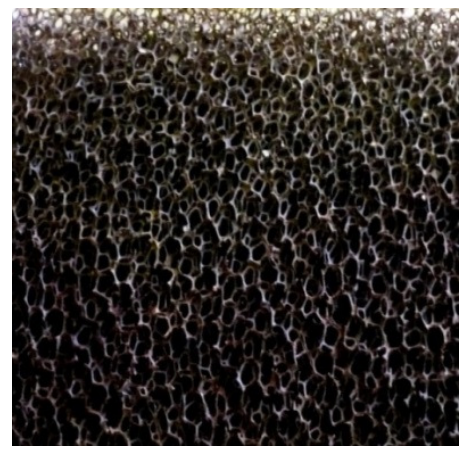

(b)

Fig. 2. The appearance of the combined packing (a) and the HPCM packing (b). 
The Table 1 shows the characteristics of packings involved in the experiment.

Table 1. The characteristics of the tested packing for biofilters.

\begin{tabular}{|c|c|c|c|}
\hline Type, material & $\begin{array}{l}\text { The specific surface, } \\
\mathrm{m}^{2} / \mathrm{m}^{3}\end{array}$ & $\begin{array}{l}\text { The free volume } \\
\text { (porousness), } \mathrm{m}^{3} / \mathrm{m}^{3}\end{array}$ & $\begin{array}{l}\text { The equivalent diameter, } \\
\mathrm{m}\end{array}$ \\
\hline \multicolumn{4}{|l|}{ Random packing } \\
\hline $\begin{array}{l}\text { Active carbon CKT-2, } 1,5 \times 5,13 \mathrm{~mm} \\
\text { (number } 1 \text { on the Fig. } 5 \text { ) }\end{array}$ & 1268 & 0.386 & 0.0012 \\
\hline $\begin{array}{l}\text { Balls of silica gel, 3-4 mm (number } 2 \\
\text { on the Fig. 5) }\end{array}$ & 1050 & 0.37 & 0.0014 \\
\hline $\begin{array}{l}\text { Wood chips, zeolite, foam (mixture), } \\
15 \mathrm{~mm} \text { (number } 3 \text { on the Fig. 5) }\end{array}$ & 320 & 0.8 & 0.010 \\
\hline \multicolumn{4}{|l|}{$\begin{array}{l}\text { Pine-cone, } 50 \times 40 \mathrm{~mm} \text { (number } 4 \text { on } \\
\text { the Fig. 5) }\end{array}$} \\
\hline $\begin{array}{l}\text { Ceramic Raschig rings, } 10 \times 10 \times 2 \mathrm{~mm} \\
\text { (number } 6 \text { on the Fig. 5) }\end{array}$ & 320 & 0.6 & 0.0075 \\
\hline \multicolumn{4}{|l|}{ Regular packing } \\
\hline $\begin{array}{l}\text { Combined packing (polymer) } \\
\text { (number } 5 \text { on the Fig. } 5 \text { ) }\end{array}$ & 1300 & 0.94 & 0.0029 \\
\hline $\begin{array}{l}\text { HPCM packing (polymer) (number } 7 \\
\text { on the Fig. 5) }\end{array}$ & 1500 & 0.92 & 0.0025 \\
\hline
\end{tabular}

The experiments were carried out on the stand, the scheme of which is presented on fig. 3. The installation general view is represented on Fig. 4.

The installation consists from packed column (1) with a two cassettes of the packing (2), air blower (3), rate-of-flow meter (4), rotameter (8), systems of air gates (a, 6$)$, differential pressure gage (5a, 5б) and the serving computer (6). In the computer this information will be transformed and stands out in a digital and graphic kind of dependence of hydraulic resistance of a packing from speed of air in a column. Air through the mist eliminator (7) leaves in atmosphere.

The gas through the rate-of-flow meter moves in a column. The gate regulate is air giving. At column irrigation through rotameter the certain expense of water moves. Differential manometers measure accordingly pressure difference in a column and the expense of submitted air.

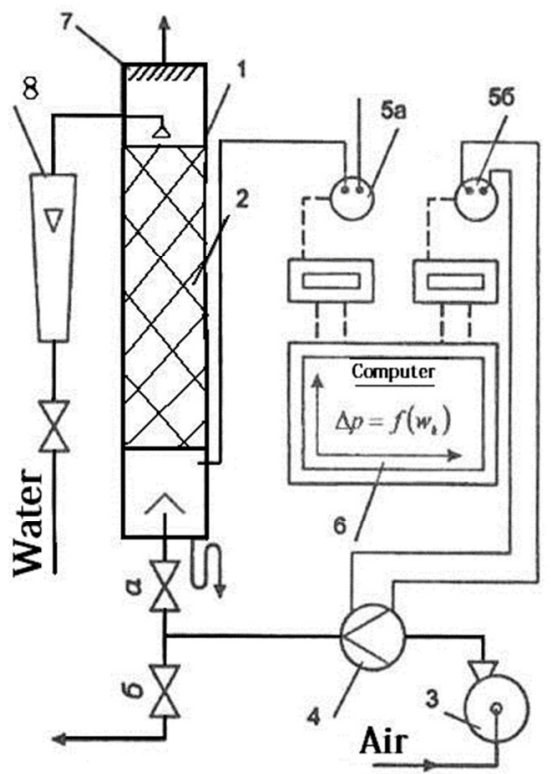

Fig. 3. The circuit of the experimental device:

1 - column; 2 - packing; 3 - ventilator; 4 - rate-of-flow meter; 5 - differential pressure gage; 6 - computer; 7 - mist eliminator; 8 - rotameter.

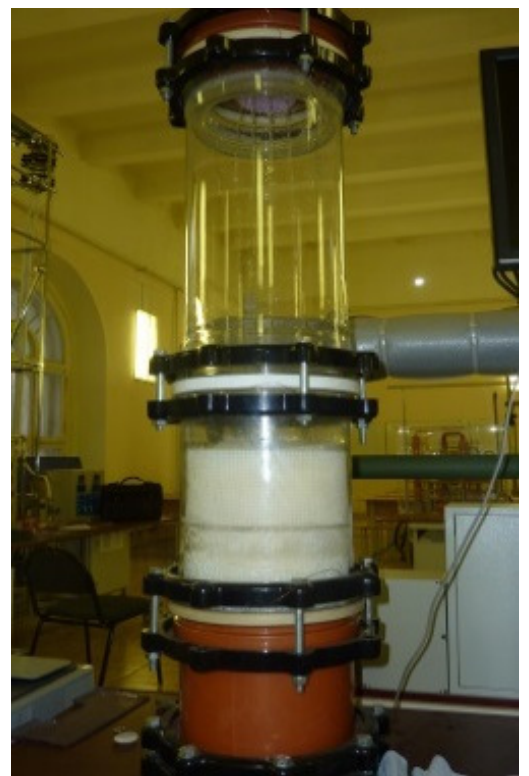

Fig. 4. The installation general view with the combined packing. 
Diameter of a column is $200 \mathrm{~mm}$, height of the column is $1000 \mathrm{~mm}$, height of packing is $800 \mathrm{~mm}$. Air flow amounted to $200 \mathrm{~m}^{3} / \mathrm{h}$, which corresponds to a velocity flow $W_{0}=0-1 \mathrm{~m} / \mathrm{s}$ in the calculation of the total cross section empty apparatus. Air temperature was $20^{\circ} \mathrm{C}$, barometric pressure is $101,3 \mathrm{kPa}$.

\section{Results and discussion}

The results of the investigations tested packing as regular and random allowed to clearly identify the boundaries of the hydrodynamic flow regime of gas stream in the biofilter. The data including different flow characteristics at different gas flow rates are confirmed in other works $[1,3,7,8]$ describing the mass transfer and other attachments. This gives an indication of the regularities of the flow and use mathematical models of mass transfer processes and for the biofiltration too. The figure 5 shows the conventional boundaries between the two flow regimes - viscous and inertia for different packing. When the gas flow rate for the tested packing (combined packing) is more $0,2 \mathrm{~m} / \mathrm{s}\left(W_{0}>2 \mathrm{~m} / \mathrm{s}\right)$, it holds inertial flow regime, in which the dependence of the viewer $P=f\left(W_{0}\right)$ in logarithmic coordinates is linear, that is obligate [4]. When the gas flow rate is less $0,2 \mathrm{~m} / \mathrm{s}$ that characteristic occurs biofilters, it holds viscous flow regime of the gas phase .

As can be seen from the graph in figure 5 the random packing active carbon CKT-2, $1.5 \times 5.13$ mm has the highest hydraulic resistance, which makes it inefficient use in the biofiltration. Significantly lower hydraulic resistance tested at the regular packing HPCM from poly urethane foam.

The figure 5 shows the results of experiments to determine the hydraulic resistance of packing for biofilters. Numbered lines graphs correspond to the numbers of packings in parentheses in the Table 1.

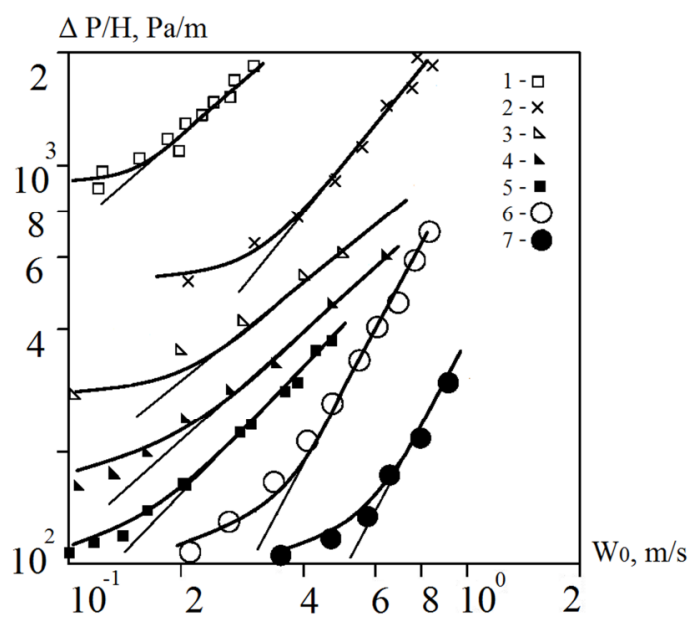

Fig. 5. The dependences of the pressure drop $\Delta \mathrm{P} / \mathrm{H}$ on the flow velocity $W_{0}$ for the different testing packings, presented on the table 1. 1- Active carbon CKT2; 2 - Balls of silica gel; 3 - Wood chips, zeolite, foam (mixture) (according to [1]); 4 - Pine-cone; 5 - Combined packing; 6 - Ceramic Raschig rings; 7 - HPCM packing.

According to the material presented in the theoretical part of this paper the deviation graph line from the construction straight line (these lines indicated in figure 5) indicates the boundary of the inertial and viscous flow regime. These borders the graphs in figure 5 can be determined for each packing. For example, the boundary between the viscous and inertial flow regimes has been shown in figure 5 for the combined packing, which is shown in figure $2 \mathrm{a}$.

The experimental data correspond to the equation (4), which allows us to conclude the process as biofiltration process with viscous flow regime of gas flow.

\section{Conclusion}

Determination of the boundary flow regime for biofiltration process is a crucial task. The optimal speed of biofiltration process lie within the viscous flow regime. In this regard, possible selection of high-performance packing on performance required.

Biofiltration defined hydrodynamic regime, marked its boundaries for packings shown in Table 1.

According to the research proposed high performance packing (Fig. 2a). This packing consists from filamentary structure, packed in lavsan net with bilateral effect of fluid flow, which allows to optimize the process for the liquid phase, according to the properties of the viscous flow regime. 


\section{Acknowledgements}

The authors wish to express their gratitude and special thanks to Sergey Parkhomenko, Mikhail Vindyukov, Zagustina Natalia, Zhukov Vitaliy for help in organizing and conducting experiments under conditions close to real production.

\section{References}

[1] Pushnov, A.; Baltrenas, P.; Kagan, A.; Zagorskis, A. 2012. Aerodinamica vozduhoochistnich ustroistv s zernistim sloem [The aerodynamics air cleaning devices with granular layer]. Vilnius: Technica, $348 \mathrm{p}$.

[2] Baltrenas, P.; Zigmontine, A.; Vaskunaite, R. 2004. Oro valymo biotechnologijos [Biotechnology of air purification]. Vilnius: Technica, 205 p.

[3] Veprickiy, A.; Zhukov, V.; Zagustina, N. 2012. IV mezdunarodniy kongress "Cvetnie metalli" [ Fourth International Congress of non-ferrous metals], Application of biological purification technology for gas emissions alphaset-process.

[4] Kagan, A. M.; Yudina, L. A.; Pushnov, A. S. 2008. Gidravlicheskoe soprotivlenie i udelnia poverhnost nereguliarnich nasadok [Hydraulic resistance and surface area of irregular attachments], Chimicheskaya promislennost [The chemical industry] 85(3): 147-150.

[5] Ramm, V. M. 1976. Absorbtsiya gazov [Absorption of gases]. Moscow: Khimiya. 656 p.

[6] Balandis, A.; Leskauskas, B.; Sinkunas, S.; Vaickelionis, G.; Valancius, Z.2007. Chemijos inzineria II knyga Vadovelis. Kaunas: Technologija, 533 p.

[7] Laptev, A. 2007. Modeli pogranichnogo sloya I rashet teplomassoobmennich processov [Boundary layer model and calculation of heat and mass transfer processes7. Kazan, p.500.

[8] Laptev, A. G.; Farakhov, M. I.; Mineev, N. G. 2010. Osnovy rascheta i modernizatsiya teplomassoobmennykh ustanovok v neftekhimii [Fundamentals of heat and mass transfer and modernization of units in the petrochemical industry]. Kazan:Kazan State Power Engineering University Publishing House. $572 \mathrm{p}$.

[9] Mitin, A.; Nikolaikina, N.; Zagustina, N.; Pushnov, A. 2013. Effectivnost processa biologicheskoi ochistki gaza [The efficiency of the biological gas purification].Aktualnie voprosi himicheskoi tehnologii I zaschiti sredi. Sbornic materialov III Vserossiiskoi conferncii s mezdunarodnim uchastiem [Topical issues of chemical engineering and environmental protection. Collected materials III All-Russian conference with international participation], Novocheboksarsk, p.63. 